\title{
Fenologia e produção do pinhão-manso cultivado com diferentes fontes de adubação ${ }^{1}$
}

\author{
Phenology and production of jatropha when grown with different sources of \\ fertilisation
}

\author{
Josely Dantas Fernandes ${ }^{2}$, Lucia Helena Garófalo Chaves ${ }^{3 *}$, José Pires Dantas ${ }^{4}$ e José Rodrigues Pacífico da \\ Silva ${ }^{5}$
}

\begin{abstract}
RESUMO - Objetivou-se com este trabalho descrever os períodos de formação de folhas novas, abscisão foliar, inflorescência e maturação dos frutos do pinhão-manso, Jatropha curcas L., bem como, determinar algumas variáveis de produção desta espécie em dois ciclos de cultivo adubada com diferentes fontes de adubação no município de RemígioPB. Utilizou-se o delineamento em blocos casualizados com cinco tratamentos e quatro repetições. Os tratamentos foram constituídos por diferentes fontes de adubação. Durante os meses de maio de 2007 a novembro de 2009 fez-se avaliações mensais dos eventos fenológicos e de produção do pinhão-manso. Independente do tratamento utilizado, a formação de folhas novas foi observada durante o período chuvoso e a abscisão foliar durante os meses mais frios e os de maior estiagem. A floração, no primeiro ciclo de cultivo, iniciou-se com o fim da estação chuvosa com a utilização do composto orgânico II (F3), já no segundo ciclo, as primeiras inflorescências foram observadas no início da estação chuvosa nas plantas adubadas com composto orgânico I (F2) e esterco de curral (F5). Em todos os tratamentos o tempo verificado entre a emissão das inflorescências até a maturação fisiológicas dos frutos foi de aproximadamente 120 dias. Na primeira colheita, as fontes de adubação não diferiram entre si em nenhuma variável de produção, entretanto, na segunda colheita, além de haver um aumento na produção, o composto orgânico I (F2) e o esterco de curral (F5) foram os que promoveram os melhores resultados.
\end{abstract}

Palavras-chave: Pinhão-manso. Fenologia vegetal. Floração.

\begin{abstract}
The objective of this work was to describe the periods of new-leaf formation, leaf abscission, the flowering and fuit-maturity of jatropha, Jatropha curcas L., as well as to determine some production variables of this species, in two crop cycles, fertilized with different sources of nutrient, in the municipality of Remígio, in the state of Paraíba. A randomized block design with five treatments and four replications was used. The treatments consisted of different sources of fertilization. During the months of May, 2007 to November, 2009 monthly evaluations of phenological events and the production of jatropha were made. Regardless of the treatment used, formation of new leaves was observed during the rainy season, and leaf abscission during both the colder and dryer months. Flowering in the first crop cycle began with the end of the rainy season, when using the organic compound II (F3), whereas in the second cycle, the first instances of inflorescence were observed at the start of the rainy season in those plants fertilized with the organic compound I (F2) and manure (F5). In all treatments the time verified between the instances of inflorescence and the physiological maturity of the fruit was approximately 120 days. For the first harvest, the sources of fertilizer did not produce any differences for any of the production variables, however, for the second harvest, besides there being an increase in production, the organic compound I (F2) and manure (F5) were those which gave the best results.
\end{abstract}

Key words: Jatropha curcas. Plant phenology. Flowering.

\footnotetext{
*Autor para correspondência

${ }^{1}$ Recebido para publicação em 23/10/2011; aprovado em 26/09/2012

Parte da Tese do primeiro autor apresentada ao Programa de Pós-Graduação em Recursos Naturais de UFCG

${ }^{2}$ Departamento de Agroecologia e Agropecuária, CCAA/UEPB, Lagoa Seca-PB, Brasil, joselysolo@ yahoo.com.br

${ }^{3}$ Departamento de Engenharia Agrícola, CTRN/UFCG, Avenida Aprígio Veloso 882, Campina Grande-PB, Brasil, 58.429-105, lhgarofalo@ hotmail.com

${ }^{4}$ Departamento de Química, CCT/UEPB, Campina Grande-PB, Brasil, gpcnpq@ terra.com.br

${ }_{5}^{5}$ Departamento de Agroecologia e Agropecuária, CCAA/UEPB, Lagoa Seca-PB, Brasil, rodriguespacifico@yahoo.com.br
} 


\section{INTRODUÇÃO}

O pinhão-manso é uma planta arbustiva, provavelmente nativa da América do Sul, mas amplamente cultivado ao longo da América Central, África e Ásia. No mundo existem diversas espécies de pinhão, mas no nordeste brasileiro, as espécies mais conhecidas são: Jatropha molissima (Pohl) Baill., Jatropha gossypiifolia L. e Jatropha curcas L. (ALBUQUERQUE; ANDRADE, 2002).

Poucos são os trabalhos publicados quanto à fenologia do pinhão-manso $\mathrm{e}$, além disso, são complexos, apresentando padrões irregulares de difícil reconhecimento. Para Santos et al. (2010), as principais fenofases observadas em estudos fenológicos são a abscisão foliar, formação de folhas novas, floração e frutificação. $O$ número de flores femininas e sua fecundação determinam quantos frutos e sementes serão desenvolvidas. Segundo Jongschaap et al. (2007), o início do florescimento ocorre após o inverno, quando a temperatura e a precipitação são reduzidas podendo se tornar contínuo por períodos prolongados, de acordo com a disponibilidade de água no solo.

A precipitação pluviométrica é um dos eventos climáticos que mais influencia na fenologia da maioria das espécies da caatinga (AMORIM; SAMPAIO; ARAÚJO, 2009; DALLACORT et al., 2010). Esta informação corrobora com os dados de Parente et al. (2009) que, após estudarem a fenologia do pinhão (Jatropha mollissima Baill) em uma caatinga no cariri paraibano, constataram efeito acentuado da precipitação sobre os parâmetros fenológicos, apresentando esta espécie, floração imediata após as primeiras chuvas, frutificação em meados do período chuvoso, bem como um curto período de manutenção das folhas, mostrandose bastante sensível ao déficit hídrico.

Segundo Bulhão e Figueiredo (2002), além da precipitação, a disponibilidade de água para a planta também deve ser considerada em estudos fenológicos. Tal informação corrobora com os dados de Borchert, Rivera e Hagnauer (2002) na qual verificaram em diferentes famílias de espécies decíduas, de caule suculento, encontradas na floresta de Guanacaste, Costa Rica, ausência de abscisão foliar em dezembro e indução de brotações em abril coincidindo com o aumento do fotoperíodo. Outro fator que favorece o desenvolvimento fenológico e de produção do pinhão-manso (Jatropha curcas) é a adubação, principalmente quando aplicado na forma organomineral (SILVA et al., 2011).

Mesmo havendo incentivo para o cultivo do pinhão-manso em grande escala, há escassez de estudos sistemáticos objetivando melhores rendimentos, especialmente no que diz respeitoàs exigências nutricionais da cultura. Sabe-se, apenas, que o crescimento da planta e o rendimento são bastante influenciados pela aplicação de fertilizantes inorgânicos e que durante a produção dos frutos uma elevada quantidade de nutrientes do solo é extraída (LAVIOLA; DIAS, 2008; MOHAPATRA; PANDA, 2011). Não obstante, ainda não está claro se o cultivo do pinhão-manso é sócio-economicamente viável quando é cultivado em condições de sequeiro e adubado organicamente (ACHTEN et al., 2008).

Pouco se conhece sobre adubação versus aspectos de desenvolvimento e produtividade do pinhãomanso. Assim, a determinação de padrões fenológicos e produtivos são relevantes para a compreensão da dinâmica da cultura e para planos de manejo. Além disso, estudos sobre florescimento e frutificação são indispensáveis para compreender o processo de formação e maturação das sementes o que serve de auxílio na realização da colheita, fase esta, dispendiosa devido à maturação irregular dos frutos. Diante disso, objetivouse descrever os períodos de formação de folhas novas, abscisão foliar, inflorescência e maturação dos frutos, bem como, determinar algumas variáveis de produção do pinhão-manso em dois ciclos de cultivo com diferentes fontes de adubação no município de Remígio-PB.

\section{MATERIAL E MÉTODOS}

$\mathrm{O}$ experimento foi realizado em condições de campo e de sequeiro na propriedade rural Jacaré, município de Remígio-PB, (latitude 6 ${ }^{\circ} 53^{\prime} 00^{\prime}$ 'Sul; longitude $36^{\circ} 02^{\prime} 00^{\prime \prime} \mathrm{W}$, com altitude de $470 \mathrm{~m}$ ), no período de maio de 2007 a novembro de 2009. O clima é classificado, conforme Koppen, em As', quente e úmido com chuvas de outono-inverno, com pluviosidade média anual de $700 \mathrm{~mm}$ e déficit acentuado durante quatro a cinco meses. Os dados climáticos no local do experimento encontram-se na Figura 1.

Antes da instalação do experimento, amostras de Neossolo Regolítico eutrófico foram coletadas, secas ao ar, passadas em peneira com malha de $2 \mathrm{~mm}$ de abertura e caracterizadas química e fisicamente segundo os métodos adotados pela Empresa Brasileira de Pesquisa Agropecuária (1997), tendo apresentado os seguintes resultados: areia $=935,1 \mathrm{~g} \mathrm{~kg}^{-1}$; silte $=30,1 \mathrm{~g} \mathrm{~kg}^{-1}$; argila $=$ $34,8 \mathrm{~g} \mathrm{~kg}^{-1} ; \mathrm{pH}\left(\mathrm{H}_{2} \mathrm{O}\right)=6,17 ; \mathrm{Ca}=1,12 \mathrm{cmol}_{\mathrm{c}} \mathrm{kg}^{-1} ; \mathrm{Mg}=$ $0,85 \mathrm{cmol}_{\mathrm{c}} \mathrm{kg}^{-1} ; \mathrm{Na}=0,06 \mathrm{cmol}_{\mathrm{c}} \mathrm{kg}^{-1} ; \mathrm{K}=0,11 \mathrm{cmol}_{\mathrm{c}} \mathrm{kg}^{-1}$; $\mathrm{Al}=0,16 \mathrm{cmol}_{\mathrm{c}} \mathrm{kg}^{-1} ; \mathrm{MO}=11 \mathrm{~g} \mathrm{~kg}^{-1} ; \mathrm{P}=7,7 \mathrm{mg} \mathrm{kg}^{-1}$.

Adotou-se o delineamento experimental em blocos casualizados com cinco tratamentos e quatro repetições. Os tratamentos consistiram nas seguintes fontes de adubação: F1- Testemunha absoluta (solo na sua condição 
Figura 1 - Médias mensais da precipitação pluvial (barras) e temperatura (linha), registrada durante a condução dos experimentos no município de Remígio-PB, no período de maio de 2007 a novembro de 2009 segundo dados da Agência Executiva de Gestão das Águas do Estado da Paraíba (AESA)

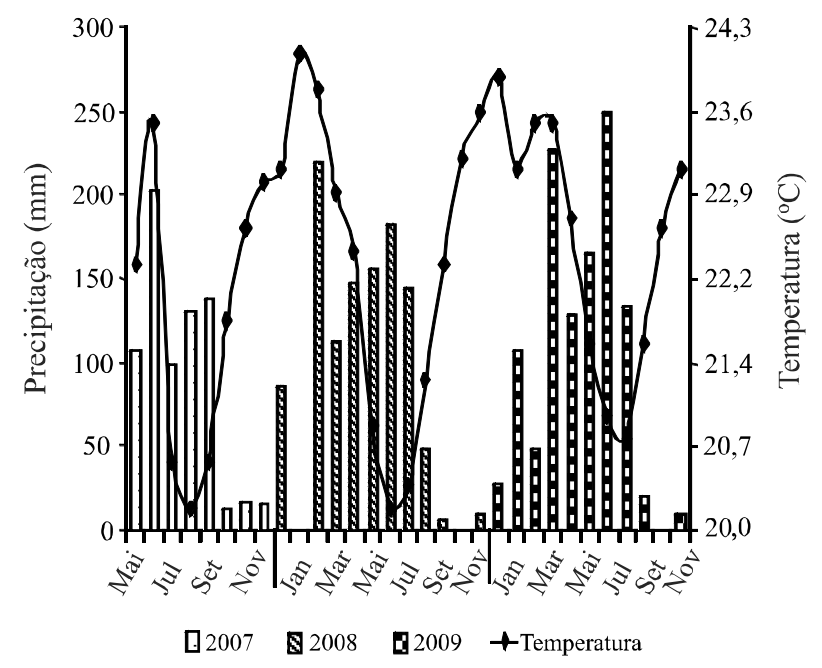

natural de fertilidade); F2- Composto Orgânico I (12 kg/ cova de composto orgânico formado por decomposição de vegetais); F3- Composto Orgânico II (12 kg/cova de composto orgânico formado por decomposição de vegetais enriquecidos com pó de rocha potássica, fosfática, pó de telha, e cinza); F4- Adubação mineral (em fundação: $40 \mathrm{~g}$ de $\mathrm{N} ; 177,77 \mathrm{~g}$ de $\mathrm{P}_{2} \mathrm{O}_{5} ; 26,66 \mathrm{~g}$ de $\mathrm{K}_{2} \mathrm{O} ; 22,86 \mathrm{~g}$ de Zn; 82,05 g de $\mathrm{Mg} ; 22,60 \mathrm{~g}$ de B; $16 \mathrm{~g}$ de $\mathrm{Cu} ; 14,28 \mathrm{~g}$ de $\mathrm{Mn}$, por cova; 45 dias após o plantio, realizou-se adubação nitrogenada aplicando 40 g de N/cova); F5- Adubação orgânica com esterco de curral curtido (12 kg/cova). Como fonte de nutrientes utilizou-se o sulfato de amônia $\left(\mathrm{NH}_{4}\right)_{2} \mathrm{SO}_{4}$, superfosfato simples (SSP), cloreto de potássio $(\mathrm{KCl})$ e sulfato de magnésio $\left(\mathrm{MgSO}_{4} \cdot 7 \mathrm{H}_{2} \mathrm{O}\right)$. $\mathrm{O}$ boro foi aplicado na forma de tetraborato de boro (bórax) e os demais micronutrientes na forma de sulfato $\left(\mathrm{CuSO}_{4} .5 \mathrm{H}_{2} \mathrm{O} ; \mathrm{ZnSO}_{4}\right.$. $\mathrm{H}_{2} \mathrm{O}$ e $\left.\mathrm{MnSO}_{4} \cdot 3 \mathrm{H}_{2} \mathrm{O}\right)$.

O esterco de curral e os compostos de lixo foram caracterizados quimicamente cujos resultados são apresentados na Tabela 1 .
O plantio do pinhão-manso foi realizado em 15/05/2007 com mudas de cinco meses de idade. O espaçamento entre plantas foi de 2,0 $\mathrm{m}$ x 2,0 m em covas de $0,40 \mathrm{~m} \times 0,40 \mathrm{~m} \times 0,40 \mathrm{~m}$, correspondendo a 2.500 plantas/ha. A área total do experimento foi de $1.280 \mathrm{~m}^{2}$. As parcelas experimentais foram constituídas por 16 plantas, contudo, apenas quatro plantas das duas fileiras centrais numa área útil de $16 \mathrm{~m}^{2}$ foram utilizadas para as avaliações fenológicas e de produção; durante a condução do experimento, as plantas daninhas foram controladas com capinas manuais.

As características fenológicas e de produção avaliadas foram: formação de folhas novas e inflorescência, abscisão foliar, maturação do fruto, número de frutos por planta (NFP), massa total dos frutos por planta (MTF), massa do fruto (MF), massa de 100 grãos, produção de grãos por planta (PGP), número de inflorescência (NINF) e rendimento percentual de grãos (RPG) calculado conforme a equação 1 .

$$
R P G=\frac{P T}{P T F} x 100
$$

Onde: $\mathrm{RPG}=$ Rendimento percentual de grãos $(\%) ; \mathrm{PT}=$ Produtividade total de frutos $\left(\mathrm{kg} \mathrm{planta}^{-1}\right)$; $\mathrm{PTF}=$ Produtividade total de frutos $\left(\mathrm{kg} \mathrm{planta}^{-1}\right)$.

A coleta dos dados fenológicos foi realizada mensalmente durante os meses de maio de 2007 a novembro de 2009 e as variáveis de produção foram analisadas durante dois ciclos produtivos.

Acolheita dos frutos foi realizada quando os mesmos apresentavam coloração amarelo escuro. Em função dos tratamentos, realizou-se a secagem dos grãos em estufa de circulação forçada de $\operatorname{ar}\left( \pm 60^{\circ} \mathrm{C}\right)$ até os mesmos atingirem peso constante. Após este procedimento, determinou-se o teor de umidade dos grãos em base seca, cujo resultado foi em média $9,05 \%$ b.s.

Para fins de análise estatística, os dados relativos ao número de frutos por planta (NFP) e ao número de inflorescência (NINF) foram transformados em raiz quadrada de $\mathrm{x}+1$; em relação ao rendimento percentual

Tabela 1 - Características químicas dos compostos orgânicos e do esterco bovino utilizados no experimento

\begin{tabular}{|c|c|c|c|c|c|c|c|c|c|c|c|c|}
\hline \multirow{3}{*}{ Adubos orgânicos } & \multicolumn{12}{|c|}{ Características químicas } \\
\hline & $\mathrm{N}$ & $\mathrm{P}$ & $\mathrm{K}$ & $\mathrm{Na}$ & $\mathrm{Ca}$ & $\mathrm{Mg}$ & $\mathrm{S}$ & $\mathrm{Cl}$ & $\mathrm{Zn}$ & $\mathrm{Fe}$ & $\mathrm{Mn}$ & $\mathrm{Cu}$ \\
\hline & \multicolumn{8}{|c|}{ 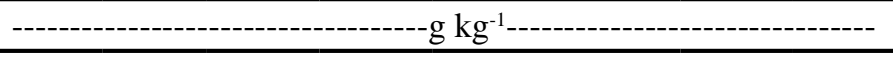 } & \multicolumn{4}{|c|}{-------------mg kg-1'-------- } \\
\hline Composto Orgânico I & 9,12 & 4,82 & 7,05 & 0,89 & 17,61 & 2,67 & 0,45 & 5,6 & 73,23 & 8467 & 246 & 18,19 \\
\hline Esterco & 8,23 & 2,7 & 11,95 & 0,74 & 10,56 & 3,86 & 0,45 & 5,49 & 44,93 & 3872 & 167 & 10,82 \\
\hline Composto Orgânico II & 8,92 & 7,37 & 7,05 & 1,01 & 21,13 & 3,37 & 0,42 & 3,83 & 75,05 & 10590 & 265 & 18,19 \\
\hline
\end{tabular}


de grãos (RPG) foram transformados em arco seno da raiz quadrada de $\mathrm{x} / 100$. Em seguida, procedeu-se, assim como para as demais variáveis, à análise de variância, pelo teste $\mathrm{F}$, e as médias, comparadas pelo teste de Tukey a 5\% de significânica, empregando-se o Programa de Análise Estatística - SISVAR (FERREIRA, 2000). A análise estatística foi feita em conjunta, ou seja, foi feita em blocos e em parcelas subdivididas no tempo (ano de produção), no entanto, os dados entre os anos não foram comparados porque não faz sentido, pela própria biologia da planta.

\section{RESULTADOS E DISCUSSÃO}

Com todas as fontes de adubação, entre os meses de junho a outubro de 2007 e dezembro de 2008 a março de 2009, houve formação de novas folhas (Figura 2). Em 2007, o surgimento de novas folhas ocorreu nos meses de menor temperatura, contudo, nos anos posteriores, com a estabilização da planta no campo, observou-se a formação de novas folhas logo após as primeiras chuvas quando a temperatura apresentava em média $23,5^{\circ} \mathrm{C}$. Maya e Arriaga (1996) e Sayer e Newbery (2003), observaram surgimento de novos brotos em Jatropha cinerea, Jatropha cuneata e Jatropha gaumeri com o início da estação chuvosa.

No ano de 2007 e durante o início dos períodos chuvosos (janeiro a março de 2008 e 2009) não ocorreu a abscisão foliar. Porém, esta abscisão iniciou-se no final da fase reprodutiva, compreendendo os meses de maio a dezembro de 2008 e de abril a setembro de 2009. Nestes períodos foram registradas as menores temperaturas, (julho de 2008 e agosto de 2009) e os menores índices pluviométricos (outubro a dezembro de 2008) (Figura 1).

De acordo com Maes, Achten e Muys (2009), a abscisão foliar verificada no pinhão-manso lhe garante o uso eficiente da água no período de estiagem, iniciando-se no final do período chuvoso e durante a época seca. Amorim, Sampaio e Araújo (2009) também verificaram, na caatinga do seridó norteriograndense, abscisão foliar em plantas de pinhão bravo logo após o término da estação chuvosa.

Estes resultados sugerem que, em condições de sequeiro, a abscisão foliar está ligada à própria biologia da cultura, já que foi verificada em todas as plantas, independente da fonte de adubação utilizada. Além disso, a abscisão e a produção de folhas ocorreram em épocas determinadas, ficando o pinhão-manso por um período de tempo quase ou totalmente sem folhas, corroborando com as informações de Santos e Takaki (2005).
Figura 2 - Fenograma do pinhão-manso adubado com diferentes fontes de adubação. Testemunha (F1), composto orgânico I (F2), composto orgânico II (F3), adubação mineral (F4) e esterco de curral (F5)
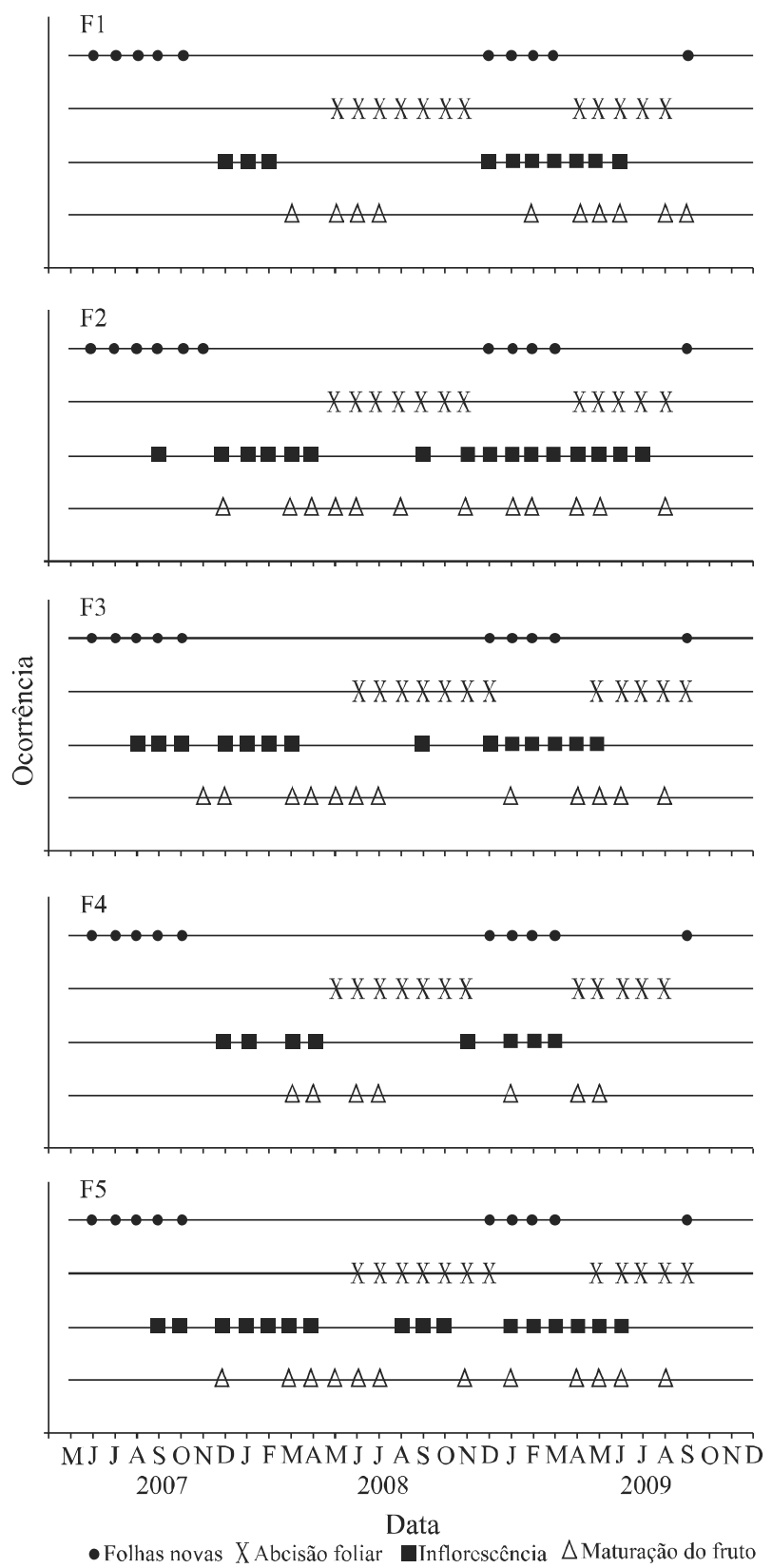

Durante o período de 32 meses (maio de 2007 a novembro de 2009), referente à condução do experimento, com todas as fontes de adubação, foram obtidas duas produções. A primeira floração iniciou-se com a aplicação do composto orgânico II (F3) em agosto/2007, terminando no mês de abril/2008, com utilização do pinhão-manso o composto orgânico I (F2), adubo mineral (F4) e esterco de curral (F5). Este período compreendeu a primeira 
produção, iniciando com o fim da estação chuvosa (setembro/2007), prolongando-se na estiagem (outubro a dezembro/2007) e encerrando-se com o início da estação chuvosa (abril/2008). Considerando-se que o plantio foi realizado com mudas de cinco meses de idade, a primeira inflorescência do pinhão-manso (F3) surgiu quando as mesmas apresentavam oito meses de idade.

A segunda floração foi iniciada em agosto/2008 encerrando-se em julho/2009 com a utilização das fontes F5 e F2, respectivamente. Contudo, foi com o início da estação chuvosa (janeiro/2009 a junho/2009) que se verificou o maior número de inflorescências, encerrandose com a época fria (julho/2009). Maya e Arriaga (1996), estudando a fenologia reprodutiva em Jatropha cinerea e Jatropha cuneata, constataram que a floração da Jatropha foi significativamente sazonal, concentrando-se durante a estação úmida e apresentando correlação significativa com a precipitação e temperatura.

Nos dois anos de produção, verificou-se baixa ocorrência de inflorescência nas plantas adubadas com a fonte mineral (F4) (4 meses) e maiores ocorrências com a utilização das fontes orgânicas, em média oito meses (Figura 2).

Independente da fonte de adubação, o tempo registrado desde a emissão das inflorescências até a maturação fisiológica dos frutos foi de, aproximadamente, 120 dias. $\mathrm{O}$ fruto foi considerado maduro quando os mesmos apresentaram coloração marrom escuro em fase de deiscência. As plantas de pinhão-manso apresentaram os primeiros frutos maduros em meados de novembro/2007, e os últimos, em agosto/2008 com as fontes F3 e F2, respectivamente. No segundo ciclo de produção, a maturação dos frutos iniciou-se em novembro/2008 com a utilização das fontes orgânicas (F2, F3 e F5) encerrando em setembro/2009 na ausência de adubo (F1).

Nos dois anos de produção foram realizadas diversas colheitas, uma vez que foram encontrados, em um mesmo cacho, frutos verdes e maduros. Segundo Larcher (2004), o período de amadurecimento e o ponto de colheita dos frutos são, sobretudo, influenciados pelas condições do clima, que pode atrasar ou acelerar os processos de maturação e envelhecimento do fruto. De acordo com Arruda et al. (2004) o início da produção do pinhão-manso é por volta do décimo mês após o plantio, mas a produção só atinge a plenitude por volta do terceiro ou quarto ano, podendo chegar aos 40 anos de idade ainda produzindo.

Quanto à produção, verificou-se pela análise de variância que a interação fontes de adubação versus ano de cultivo foi significativa apenas para as variáveis: número de frutos por planta, massa total dos frutos por planta, produção de grãos por planta e número de inflorescência (Tabela 2). Quanto aos coeficientes de variação (CV), mesmo transformando os dados de número de frutos por planta (NFP) e rendimento percentual de grãos (RPG), no primeiro ciclo de produção, os valores mostraramse superiores a $30 \%$, considerados muito altos, uma vez que o valor da precisão experimental aceitável é de até 30 \% (GOMES, 2000). Estes valores, assim como para as variáveis MTF, MF, M100G e PGP, podem ser explicados devido ao fato de o pinhão-manso não possuir uma variedade geneticamente melhorada, o que promoveu uma produção irregular entre plantas de uma mesma parcela.

No segundo ciclo de produção, os melhores resultados para número de frutos/planta (NFP) foram obtidos com as fontes orgânicas: composto orgânico I (F2)

Tabela 2 - Resumo das análises das variâncias para os dados de número de frutos por planta (NFP), massa total dos frutos por planta (MTF), massa do fruto (MF), massa de 100 grãos (M100G), produção de grãos por planta (PGP), número de inflorescência (NINF) e rendimento percentual de grãos (RPG)

\begin{tabular}{lcccccccc}
\hline \multirow{2}{*}{ FV } & \multirow{2}{*}{ GL } & \multicolumn{7}{c}{ Quadrados Médios } \\
\cline { 3 - 8 } & & NFP $^{(1)}$ & MTF & MF & M100G & PGP & NINF $^{(1)}$ & RPG $^{(2)}$ \\
\hline Bloco & 3 & $8,51^{\text {ns }}$ & $5247,1^{\text {ns }}$ & $1,618^{\text {ns }}$ & $772,2^{\text {ns }}$ & $2751,2^{\text {ns }}$ & $1,32^{*}$ & $0,148^{\text {ns }}$ \\
Fonte de adubação (F) & 4 & $21,71^{* *}$ & $17153,5^{* *}$ & $0,424^{\text {ns }}$ & $395,6^{\text {ns }}$ & $9471,8^{* *}$ & $2,05^{* *}$ & $0,056^{\text {ns }}$ \\
Resíduo (a) & 12 & 3,88 & 3113,3 & 0,660 & 385,9 & 1419,03 & 0,376 & 0,057 \\
Ano (A) & 1 & $98,92^{* *}$ & $102472,1^{* *}$ & $5,814^{* *}$ & $1873,5^{* *}$ & $52246,9^{* *}$ & $12,09^{* *}$ & $0,009^{\text {ns }}$ \\
F x A & 4 & $7,30^{* * *}$ & $11901,9^{* *}$ & $0,627^{\text {ns }}$ & $220,8^{\text {ns }}$ & $6764,3^{* *}$ & $0,899^{* *}$ & $0,018^{\text {ns }}$ \\
Resíduo (b) & 15 & 0,811 & 1607,2 & 0,206 & 112,3 & 792,6 & 0,106 & 0,020 \\
\hline CV \% (a) & 41,7 & 76,5 & 35,8 & 35,13 & 73,1 & 28,77 & 34,5 & \\
CV \% (b) & 19,1 & 54,9 & 20,0 & 18,95 & 54,6 & 15,28 & 20,5 & \\
\hline
\end{tabular}

"Significativo $(\mathrm{p}<0,05) ;{ }^{* *}$ Significativo $(\mathrm{p}<0,01)$; ${ }^{\text {ns }}$ ão significativo. ${ }^{(1)}$ Dados transformados para $\sqrt{\mathrm{x}+1} ;{ }^{(2)}$ Dados transformados para arco seno $\sqrt{\mathrm{x}} / 100$ 
e esterco bovino (F5), não diferindo suas médias entre si; os frutos colhidos com a aplicação do composto orgânico II (F3) não diferiram daqueles obtidos com as fontes F1 e F4 (Tabela 3). Silva et al. (2008), avaliando diferentes acessos de pinhão-manso, registraram o surgimento da primeira floração aos seis meses após o plantio com um total de 20 a 25 frutos/planta.

Apesar de não ter sido apresentado em tabela, o número médio de frutos/cacho foi de 4 (F1), 5 (F4 e $\mathrm{F} 5), 6(\mathrm{~F} 2)$ e $8(\mathrm{~F} 3)$ no primeiro ciclo e $5(\mathrm{~F} 1), 6(\mathrm{~F} 4)$ e 7 (F2, F3 e F5) no segundo ciclo. Sunil et al. (2007) verificaram em 162 acessos de pinhão-manso na Índia, cachos com média de 6 a 10 frutos.

Segundo Drumond et al. (2009), o pinhão-manso, no seu primeiro ano de cultivo em condições de sequeiro e adubada em fundação com $150 \mathrm{~g} /$ cova de NPK (06:24:12), produziram 50 frutos/planta. A adubação bem conduzida possibilita ganhos significativos de produtividade na maioria das plantas cultivadas. $\mathrm{O}$ pinhão-manso é uma planta que responde a doses de potássio e fósforo, promovendo um crescimento inicial rápido (ALMEIDA JÚNIOR et al., 2009; LIMA et al., 2011). Da mesma forma, a aplicação de adubos orgânicos favorece maior absorção de nutrientes pelas mudas de pinhão-manso (SILVA et al., 2011).

Quanto ao número de inflorescência, no primeiro ciclo, o menor número de emissões foi observado nas plantas adubadas com F1 (ausência de adubação) e F4 (adubação mineral), e a maior emissão nas plantas adubadas com composto orgânico II (F3). Entretanto, suas médias não diferiram entre si. $\mathrm{O}$ baixo número de inflorescência observado é explicado pela idade das plantas que, por terem um ano, encontram-se no período de juvenilidade e pela ocorrência de flores abortadas.

No segundo ciclo, o número de inflorescência aumentou com todas as fontes de adubação, sendo verificado nas plantas adubadas com composto orgânico I (F2) e esterco bovino (F5) as maiores emissões. O aumento do número de inflorescência no segundo ciclo de produção é esperado uma vez que o pinhão-manso segue a arquitetura típica de diversas euforbiáceas; a primeira inflorescência é cimeira, originando dois novos ramos onde surgiram novas florações. A influência das fontes de adubação, a partir deste período, é justificada pela decomposição e liberação gradual dos adubos orgânicos (F2 e F5). Teores adequados de nutrientes, entre eles o nitrogênio, favorecem o processo de floração do pinhão-manso como também retarda, em casos de deficiência (YONG et al., 2010).

Se, no primeiro ciclo, as médias de produção obtidas com as diferentes fontes de adubação não diferiram significativamente entre si, no segundo ciclo houve um incremento na produção de grãos de 357,7\%; $780,46 \% ; 132,67 \% ; 625,76 \%$ e $585,25 \%$ nas plantas adubadas com F1, F2, F3, F4 e F5, respectivamente, sendo que desta vez, as fontes orgânicas (F2 e F5)

Tabela 3 - Médias do número de frutos por planta (NFP), massa total dos frutos por planta (MTF), produção de grãos por planta (PGP) e número de inflorescência (NINF) nas diferentes fontes de adubação

\begin{tabular}{|c|c|c|c|c|c|c|}
\hline \multirow{2}{*}{$\begin{array}{l}\text { Ciclo de } \\
\text { produção }\end{array}$} & \multirow{2}{*}{ DMS } & \multicolumn{5}{|c|}{ Fontes de adubação } \\
\hline & & F1 & $\mathrm{F} 2$ & $\mathrm{~F} 3$ & $\mathrm{~F} 4$ & F5 \\
\hline & & \multicolumn{5}{|c|}{ - } \\
\hline Primeiro & \multirow{2}{*}{1,96} & $2,12 \mathrm{a}$ & $3,65 \mathrm{a}$ & $4,04 \mathrm{a}$ & $2,14 \mathrm{a}$ & $3,77 \mathrm{a}$ \\
\hline \multirow[t]{2}{*}{ Segundo } & & $3,72 \mathrm{~b}$ & 8,88 a & $5,68 \mathrm{~b}$ & $4,17 \mathrm{~b}$ & $9,00 \mathrm{a}$ \\
\hline & & . & - & MTF $(g)$ & --------- & ------------ \\
\hline Primeiro & \multirow{2}{*}{87,56} & 8,75 a & $26,25 \mathrm{a}$ & $36,34 \mathrm{a}$ & $8,60 \mathrm{a}$ & $31,71 \mathrm{a}$ \\
\hline \multirow[t]{2}{*}{ Segundo } & & $42,78 \mathrm{~b}$ & $220,10 \mathrm{a}$ & $86,80 \mathrm{ab}$ & $60,01 \mathrm{~b}$ & $208,10 \mathrm{a}$ \\
\hline & \multicolumn{6}{|c|}{ - } \\
\hline Primeiro & \multirow{2}{*}{61,48} & $6,24 \mathrm{a}$ & $18,12 \mathrm{a}$ & 24,79 a & $5,59 \mathrm{a}$ & 22,18 a \\
\hline \multirow[t]{2}{*}{ Segundo } & & $28,56 \mathrm{c}$ & $159,54 \mathrm{a}$ & $57,68 \mathrm{bc}$ & $40,57 \mathrm{c}$ & $151,99 \mathrm{ab}$ \\
\hline & & - & --------- & NINF* ---- & --------- & ----------- \\
\hline Primeiro & \multirow{2}{*}{0,71} & $1,31 \mathrm{a}$ & $1,68 \mathrm{a}$ & $1,82 \mathrm{a}$ & $1,32 \mathrm{a}$ & $1,77 \mathrm{a}$ \\
\hline Segundo & & $1,87 \mathrm{~b}$ & $3,55 \mathrm{a}$ & $2,40 \mathrm{~b}$ & $2,02 \mathrm{~b}$ & $3,56 \mathrm{a}$ \\
\hline
\end{tabular}

Médias seguidas de mesma letra minúscula não diferem entre si dentro do mesmo ciclo de produção, nos respectivos tratamentos (Teste de Tukey, $\mathrm{P} \leq 0,05)$. Testemunha (F1), composto orgânico I (F2), composto orgânico II (F3), adubação mineral (F4) e esterco de curral (F5). *Médias transformadas para raiz quadrada de $\mathrm{x}+1$ 
promoveram a maior produção. Este aumento já era esperado em virtude do próprio desenvolvimento da planta, porém, não foi suficiente para atingir a média sugerida por Tominaga, Kakida e Yasuda (2007), que é de 100; 500; 2.000 e $4.000 \mathrm{~g} \mathrm{planta}^{-1}$ de sementes no primeiro, segundo, terceiro e quarto anos de cultivo, respectivamente. Normalmente, quanto maior o período de tempo disponível para a planta em condições ambientais favoráveis, maior será o número de frutos formados e, portanto, maior a produtividade.

Com base nas características químicas dos adubos orgânicos (Tabela 1) e considerando o que foi aplicado ao solo como adubo químico, observa-se que o composto orgânico I (F2) foi o que apresentou maior teor de $\mathrm{N}$ e proporcionou a maior produção de grãos no segundo ciclo. Mohapatra e Panda (2011), também verificaram aumento no rendimento de frutos de pinhão-manso em função da adubação nitrogenada, obtendo uma produção máxima de 270,28 frutos/planta com uma aplicação de $60 \mathrm{~g}$ de N/planta.

Provavelmente, a poda realizada em agosto/2008 também contribuiu para que ocorresse o incremento na produção, uma vez que para Melo et al. (2008), esta prática promove a emissão de novos ramos laterais, o que aumenta a produção de frutos e sementes. Em geral, a produtividade da planta está condicionada ao número de frutos, número de sementes por fruto e massa de sementes, variando muito, dependendo da região, dos métodos de cultivo e tratos culturais, idade da cultura, bem como da regularidade pluviométrica, ação prolongada de ventos na época da estiagem ou mesmo pela fertilidade do solo.

\section{CONCLUSÕES}

1. Independente das fontes de adubação utilizada neste trabalho, a formação de folhas novas e a abscisão foliar ocorreram em períodos específicos em função das variações de precipitação;

2. O tempo entre a emissão das inflorescências e a maturação fisiológica dos frutos foi de 120 dias;

3. As maiores médias das variáveis de produção foram verificadas nas plantas adubadas organicamente, em especial com composto orgânico I (F2) e esterco bovino (F5).

\section{AGRADECIMENTOS}

Os autores agradecem ao BNB/FUNDECI pelo auxilio concedido para a execução do projeto de pesquisa.

\section{REFERÊNCIAS}

ACHTEN, W. M. J. et al. Jatropha bio-diesel production and use. Biomass and Bioenergy, v. 32, n. 12, p. 1063-1084, 2008 .

ALBUQUERQUE, U. P.; ANDRADE, L. H. C. Conhecimento botânico tradicional e conservação em uma área de caatinga no Estado de Pernambuco, Nordeste do Brasil. Acta Botânica Brasilica, v. 16, n. 3, p. 273-285, 2002.

ALMEIDA JÚNIOR, A. B. et al. Efeito de doses de fósforo no desenvolvimento inicial da mamoneira. Revista Caatinga, v. 22, n. 1, p. 217-221, 2009.

AMORIM, I. L.; SAMPAIO, E. V. S. B.; ARAÚJO, E. L. Fenologia de espécies lenhosas da caatinga do seridó, RN. Revista Árvore, v. 33, n. 3, p. 491-499, 2009.

ARRUDA, F. P. et al. Cultivo de pinhão manso (Jatropha curca L.) como alternativa para o semi-árido nordestino. Revista Brasileira de Oleaginosas e Fibrosas, v. 8, n. 1, p. 789-799, 2004.

BORCHERT, R.; RIVERA, G.; HAGNAUER, W. Modification of vegetative phenology in a tropical semideciduous forest by abnormal drought and rain. Biotropica, v. 34, n. 1, p. 27-39, 2002.

BULHÃO, C. F.; FIGUEIREDO, P. S. Fenologia de leguminosas arbóreas em uma área de cerrado marginal no nordeste do Maranhão. Revista Brasileira de Botânica, v. 25, n. 3, p. 361-369, 2002.

DALLACORT, R. et al. Aptidão agroclimática do pinhão manso na região de Tangará da Serra, MT. Revista Ciência Agronômica, v. 41, n. 3, p. 373-379, 2010.

DRUMOND, M. A. et al. Desempenho agronômico de genótipos de pinhão manso no Semiárido pernambucano. Ciência Rural, v. 40 , n. 1 , p. $44-47,2009$.

EMPRESA BRASILEIRA DE PESQUISA AGROPECUÁRIA. Centro Nacional de Pesquisa de Solos. Manual de métodos de análise de solo. 2. ed. Rio de Janeiro: CNPS, 1997. 212 p.

FERREIRA, D. F. Análise estatística por meio do SISVAR (Sistema para Análise de Variância) para Windows versão 4.0. In: REUNIÃO ANUAL DA REGIÃO BRASILEIRA DA SOCIEDADE INTERNACIONAL DE BIOMETRIA, 45., 2000, São Carlos. Anais... São Carlos: UFSCar, 2000. p. $255-258$

GOMES, F. P. Curso de Estatística Experimental. 14. ed. Piracicaba: Editora Degaspari, 2000. 477 p.

JONGSCHAAP, R. E. E. et al. Claims and facts on Jatropha curcas L. Wageningen: Plant Research International. 2007. $42 \mathrm{p}$.

LARCHER, W. Ecofisiologia vegetal. São Carlos, SP: Rima Artes, 2004. $531 \mathrm{p}$.

LAVIOLA, B. G.; DIAS, L. A. S. Teor e acúmulo de nutrientes em folhas e frutos de pinhão-manso. Revista Brasileira de Ciência do Solo, v. 32, n. 5, p. 1969-1975, 2008. 
LIMA, R. L. S. et al. Efeito da adubação fosfatada sobre o crescimento e teor de macronutrientes de mudas de pinhão manso. Revista Ciência Agronômica, v. 42, n. 4, p. 950956, 2011.

MAES, W. H.; ACHTEN, W. M. J.; MUYS, B. Use of inadequate data and methodological errors lead to an overestimation of the water footprint of Jatropha curcas, Proceedings of the National Academy of Sciences of the United States of America, v. 106, n. 34, p. E91, 2009.

MAYA, Y.; ARRIAGA, L. Litterfall and phenological patterns of the dominant overstory species of a desert scrub community in north-western Mexico. Journal of Arid Environments, v. 34, n. 1, p. 23-35, 1996.

MELO, R. D.; LEE, G. T. S.; MASSARO, R. I. Influência da Poda na Produção de Pinhão Manso (Jatropha Curcas L.). In: CONGRESSO DE INICIAÇÃO CIENTÍFICA, 16., 2008, São Carlos. Anais ... São Carlos:UFSCar, 2008. p. 381, 2008. 1CD-ROM.

MOHAPATRA, S.; PANDA, P. K. Effects of Fertilizer Application on Growth and Yield of Jatropha curcas L. in an Aeric Tropaquept of Eastern India. Notulae Scientia Biologicae, v. 3, n. 1, p. 95-100, 2011.

PARENTE, H. N. et al. Estudo fenológico do pinhão (Jatropha mollissima Baill.) em uma caatinga no Cariri paraibano. In: CONGRESSO NACIONAL DOS ESTUDANTES DE ZOOTECNIA, 19., 2009, Águas de Lindóia. Anais... Águas de Lindóia: ABZ, 2009. p. 1-3.
SANTOS, C. M. et al. Fenologia e crescimento do pinhão-manso cultivado na zona da mata do Estado de Alagoas, Brasil. Scientia Agraria, v. 11, n. 3, p. 201-209, 2010.

SANTOS, D. L.; TAKAKI, M. Fenologia de Cedrela fissilis Vell. (Meliaceae) na região rural de Itirapina, SP, Brasil. Acta Botanica Brasilica, v. 19, n. 3, p. 625-632, 2005.

SAYER, E. J.; NEWBERY, D. M. The role of tree size in the leafing phenology of a seasonally dry tropical forest in Belize, Central America. Journal of Tropical Ecology, v. 19 , n. 6, p. 539-548, 2003.

SILVA, S. G. A. et al. Caracterização da diversidade de acessos de pinhão manso In: CONGRESSO BRASILEIRO DE MAMONA, 3., 2008, Salvador. Resumos... Salvador: Embrapa Algodão, 2008.

SILVA, T. O. et al. Crescimento inicial e absorção de nutrientes por mudas de pinhão manso submetidas à adubação orgânica em solos distintos. Scientia Plena, v. 7, n. 8, p. 1-9, 2011.

SUNIL, N. et al. Assessing Jatropha curcas L. germplasm in-situ - A case study. Biomass and Bioenergy, v. 32, n. 03, p. 198-202, 2007.

TOMINAGA, N.; KAKIDA, J.; YASUDA, E. K. Cultivo de pinhão manso para produção de biodiesel. Viçosa, MG: CPT, 2007. $220 \mathrm{p}$.

YONG, J. W. H. et al. Effect of fertilizer application on photosynthesis and oil yield of Jatropha curcas L. Photosynthetica, v. 48, n. 2, p. 208-218, 2010. 